\title{
Presence of iron in polymers extruded with corrosive contaminants or abrasive fillers
}

\author{
Marcos Fernado Franco ${ }^{1}$, Renan Gadioli ${ }^{1}$ and Marco Aurelio De Paoli* ${ }^{*}$ \\ ${ }^{1}$ Laboratório de Processamento de Polímeros, Instituto de Química, Universidade Estadual de \\ Campinas - UNICAMP, Campinas, SP, Brasil \\ *madpaoli@unicamp.br
}

\begin{abstract}
Off-site measurements of the dimensions of extruder screws are used to monitor their wear. This wear causes the presence of metals in the processed polymer. We detected the presence of iron in polymers processed with corrosive contaminants or abrasive fillers. To this end we processed poly(ethylene terephthalate), PET, pure or contaminated with poly(vinyl chloride), PVC, and other thermoplastics reinforced with glass fibers, talc or vegetal fibers, and analyzed the metals in the processed materials by X-ray fluorescence spectroscopy. We show that iron dispersed in the polymer melt is generated by corrosion from the PET contaminated with PVC and by erosion from abrasive fillers. The contents of iron in the extruded polymers clearly indicate equipment wear. This contaminant acts as a polymer pro-degradant, decreasing its lifetime. Additionally, we show that the lower concentration of iron for composites with vegetal fibers indicates a lower abrasion in comparison to talc and glass fibers.
\end{abstract}

Keywords: extrusion, fibers, fillers, iron contamination, talc.

How to cite: Franco, M. F., Gadioli, R., \& De Paoli, M. A. (2019). Presence of iron in polymers extruded with corrosive contaminants or abrasive fillers. Polímeros: Ciência e Tecnologia, 29(2), e2019021. https://doi.org/10.1590/01041428.10017

\section{Introduction}

Low-carbon steel is a raw material used for mixer rotors, extruder screws and barrels. For extruder screws, hardfacings welded to the tops of flights provide additional wear resistance ${ }^{[1]}$. The presence of harder materials (i.e., pigments, like $\mathrm{TiO}_{2}$, or fillers, like talc or short glass fibers) in the polymer formulation is the main cause of wear in these tools $^{[2]}$. Erosion by chemical attack on the metal surfaces may also cause wear ${ }^{[3]}$. On a longer time scale, polymer formulations with less abrasive components, like vegetal fibers, also wear the equipment. Worn flights of conveying elements and worn tips of kneading elements reduce mixing efficiency. Increasing screw speed may compensate efficiency reduction but it accelerates wear. Measuring, controlling and replacing or repairing extruder screws or mixer rotors, after a certain degree of wear, is therefore routine in every polymer processing plant. However, to our knowledge, there are no reports on the final destination of the metals removed from the processing equipment. In all cases, iron is the metallic element predominantly removed from the tool. Since metals and their oxides are not volatile, this contaminant migrates towards the polymer melt, remaining in the bulk of the processed material during its entire life. Among the various impurities that affect the degradation of polymeric materials, impurities containing transition metals often show the most pronounced effect ${ }^{[4]}$.

Poly(ethylene terephthalate), PET, is processed by extrusion for recycling ${ }^{[5]}$. Prior to processing, it is separated and cleaned. However, due to the similarity in density with

poly(vinyl chloride), PVC, this contamination is frequently present. PVC undergoes thermal degradation at the processing temperature for PET recycling $\left(240-280{ }^{\circ} \mathrm{C}\right)$, yielding hydrochloric acid, $\mathrm{HCl}^{[6,7]}$. This contamination causes the hydrolytic degradation of PET and may cause corrosion of the screws and barrel of the extruder ${ }^{[3]}$. The determination of iron in recycled PET can be useful to indicate the extent of previous contamination of the raw material with PVC.

Metal contamination in polymers may lead to the pronounced acceleration of oxidation reactions. Goss et al. ${ }^{[8]}$ demonstrated that catalyst residue, in concentrations between 0.2 and $4.1 \mathrm{~g}$ per $1000 \mathrm{~kg}$, accelerates degradation in polypropylene, PP. Another study, involving different transition metals and polyethylenes (low, high density, linear and ultra-high molecular weight), ranks iron as the second most reactive metal for polyolefin oxidation ${ }^{[9]}$. Other authors reported that iron (III) decomposes the antioxidant additive in the oven aging of $\mathrm{PP}^{[10]}$. It was also demonstrated that iron-based oxygen scavengers affect the thermo-mechanical degradation of PP in multiple extrusions ${ }^{[1]}$. For ABS, the chemically reactive comonomer is butadiene and the effect of Iron(III) chloride on the degradation of polybutadiene was reported ${ }^{[12]}$. Additionally, the catalytic activity of transition metal oxides, including iron oxide, towards oxidation reactions is well known ${ }^{[13]}$. Thus, tracking iron in processed polymers is important to assess machine wear, to estimate the extent of metal deactivators needed to compensate its prodegradant effect and to improve the lifetime of the processed polymer. 
The aim of this work is therefore to confirm the presence of iron in polymers processed in a mixer and a single screw extruder. First, by processing PET contaminated with PVC, simulating the effects of the thermo-mechanical PET recycling process. Second, by determining the iron concentrations in different thermoplastic polymers processed with abrasive fillers and comparing them to the pure materials.

\section{Materials and Methods}

\subsection{Materials}

Pellets of commercial virgin bottle-grade PET (PET-btg, Solvay, Poços de Caldas, Brazil), Table 1, and bottle-grade PVC (PVC-btg), from bottles purchased locally, were used. Prior to processing, PET-btg pellets were dried in a vacuum oven at $160{ }^{\circ} \mathrm{C}$ and $27 \mathrm{kPa}$ for $6 \mathrm{~h}$ and stored in a desiccator with silica under a vacuum. Chips from milled PVC bottles were mixed with PET-btg in the proportions indicated below.

We used, in the form of pellets, poly(acrylonitrile-cobutadiene-co-styrene), ABS, poly(butylene terephthalate), PBT, polyamide-6, PA-6, and high-density polyethylene,

Table 1. PET-btg specifications provided by the producer.

\begin{tabular}{lclc}
\hline \multicolumn{1}{c}{ Characteristic } & Specification & Method & Unit \\
\hline Intrinsic viscosity & $0.80 \pm 0.03$ & ASTM D 2857 & $\mathrm{dL} \mathrm{g}^{-1}$ \\
Density & $>1.39$ & ASTM D 1505 & $\mathrm{g} \mathrm{cm}^{-3}$ \\
Residual Acetaldehyde & $<3$ & ASTM D 4526 & $\mathrm{ppm}$ \\
Crystallinity (density) & $>48$ & PD-12021 & $\%$ \\
Chips Weight & 1.5 & PD-12029 & $\mathrm{g} / 100 \mathrm{Chips}$ \\
Humidity & $<0.4$ & PD-12012 & $\mathrm{wt} . \%$ \\
Melting Temperature & $240 \pm 5$ & ASTM D 3418 & ${ }^{\circ} \mathrm{C}$ \\
Color: L & $79 \pm 3$ & ASTM D 1925 & $\mathrm{CIE}$ \\
\hline
\end{tabular}

\# Methodology used by the producer.

Table 2. PVC mass and concentration as a contaminant for samples processed in the internal mixer.

\begin{tabular}{ccc}
\hline Samples & PVC-btg mass $(\boldsymbol{\mu g})$ & PVC concentration $\left(\mathbf{m g ~ k g}^{-1}\right)$ \\
\hline M1 & 0.0 & 0.000 \\
M2 & $30.4 \pm 0.2$ & $0.61 \pm 0.02$ \\
M3 & $52.5 \pm 0.5$ & $1.05 \pm 0.05$ \\
M4 & $59.1 \pm 0.4$ & $1.12 \pm 0.04$ \\
\hline
\end{tabular}

Table 3. PVC-btg mass and concentration as a contaminant of $2.0 \mathrm{~kg}$ of PET-btg. Samples processed in the extruder.

\begin{tabular}{ccc}
\hline Sample & PVC-btg mass $(\boldsymbol{\mu g})$ & PVC-btg concentration $\left(\mathbf{m g ~ k g}^{-1}\right)$ \\
\hline E1 & $30.00 \pm 0.04$ & $0.015 \pm 0.04$ \\
E2 & $70.00 \pm 0.02$ & $0.035 \pm 0.02$ \\
E3 & $110.00 \pm 0.03$ & $0.055 \pm 0.03$ \\
E4 & $120.00 \pm 0.10$ & $0.060 \pm 0.01$ \\
\hline
\end{tabular}

HDPE, all in the pure form and reinforced with 20 or $30 \mathrm{wt} . \%$ of short glass fibers (SABIC, Campinas, Brazil) and PP, pure (Braskem, Triunfo) and reinforced with $20 \mathrm{wt} . \%$ of short glass fibers and $10 \mathrm{wt}$ \% talc (Borealis, Itatiba, Brazil).

Composites reinforced with cellulose fibers were processed and obtained as described in previous works: PP ${ }^{[14]}, \mathrm{HDPE}^{[15]}$ and PA-6 ${ }^{[16]}$.

\subsection{Processing}

\subsubsection{Internal mixer}

The samples were processed in an internal mixer Haake Rheomix with counter-rotating rotors connected to a torque rheometer Haake Rheocord 90. They were prepared using a previously dried, fixed amount of $50.0 \mathrm{~g}$ of PET-btg. In each experiment, PVC-btg was added to the mixing chamber in quantities ranging from 0.0 to $81.5 \mu \mathrm{g}$, with a $5.0 \mu \mathrm{g}$ increase for each processing. The mixing conditions were $250{ }^{\circ} \mathrm{C}$ and $50 \mathrm{rpm}$ for $5 \mathrm{~min}$ with closed and locked mixing chamber ${ }^{[17]}$. The concentrations were higher than those set for extrusion due to limitations of weighing lower quantities in the $\mu \mathrm{g}$ range. The results are presented for the four selected samples shown in Table 2.

\subsubsection{Extruder}

PVC-btg was mixed as a contaminant to a previously dried, fixed amount of $2.0 \mathrm{~kg}$ of PET-btg, Table 3 , and the samples were processed in the single screw extruder Wortex WEX30 (Campinas, Brazil), L/D = 30, D = $32 \mathrm{~mm}$ with five heating zones. A monofilament Maddock mixing screw was used at a rotation speed of $100 \mathrm{rpm}^{[18]}$. The temperature profiles are presented in Table 4. The strands cooled in a water tank were cut in the form of pellets and dried for $4 \mathrm{~h}$ in an oven at $100^{\circ} \mathrm{C}$.

The same extruder was used to reprocess ABS, PBT, PA-6, PP and HDPE reinforced with glass fibers or talc using a double filament screw with a mixing element at zone 3 and rotation speed of $50 \mathrm{rpm}$. The temperature profiles are presented in Table 4. All samples were reprocessed five times, with strand cutting and drying at each processing cycle.

\subsection{X-ray fluorescence, XRF, analyses}

PET samples were analyzed in triplicate in a Shimadzu EDX 700 benchtop EDXRF X-ray analyzer, with an X-ray rhodium tube and a $\mathrm{Si} / \mathrm{Li}$ semiconductor detector, and irradiated at ambient conditions for $500 \mathrm{~s}$. Other conditions were: $25 \% \mathrm{Si} / \mathrm{Li}$ dead time, $10 \mathrm{~mm}$-collimated beam, $50 \mathrm{kV}$ voltage and $10 \mu \mathrm{A}$ current applied to the Rh tube. The energy range was 0 to $40.96 \mathrm{keV}$, with a $0.02 \mathrm{keV}$ resolution ${ }^{[19]}$.

For the samples reinforced with glass fibers, cellulose fibers or talc, we cut sections of three regions of the processed

Table 4. Temperature profiles $\left({ }^{\circ} \mathrm{C}\right)$ used for extrusion: numbers in the samples correspond to the concentration of glass fibers, GF, or talc, $T$. $\mathrm{Z}$ refers to the extruder heating zones.

\begin{tabular}{|c|c|c|c|c|c|c|c|}
\hline Sample & PET & PET/PVC & ABS20GF & PBT30GF & PA30GF & PE30GF & PP20GF10T \\
\hline Z1-Rear & 220 & 220 & 210 & 220 & 220 & 195 & 170 \\
\hline Z2 & 260 & 260 & 230 & 240 & 260 & 210 & 220 \\
\hline $\mathbf{Z 3}$ & 275 & 275 & 250 & 250 & 280 & 220 & 230 \\
\hline $\mathbf{Z 4}$ & 280 & 280 & 280 & 265 & 290 & 235 & 250 \\
\hline Z5-Nozzle & 280 & 280 & 270 & 260 & 275 & 225 & 240 \\
\hline
\end{tabular}


strand, pressed at $220^{\circ} \mathrm{C}$ to produce films of $1.0 \mathrm{~cm}^{2}$. Films were also obtained in triplicate from pellets of the pure polymers. These films were quantitatively analyzed in a Shimadzu XRF1800 sequential analyzer.

\section{Results and Discussions}

Processing in an extruder or an internal mixer implies high shear rates ${ }^{[20,21]}$. The removal of metal from the equipment to the resin through friction, shear and/or chemical attack by some degrading product generated during processing is likely to occur. Using XRF analysis and by comparing a processed with a non-processed sample, it is possible to demonstrate this metal migration from the processing equipment to the polymer sample ${ }^{[22]}$.

\subsection{PET contaminated with PVC}

Figure 1 shows a comparison of the XRF spectra of PET-btg samples, before, virgin PET, and after processing, $\mathrm{M} 1$, in the twin-rotor internal mixer. The presence of a signal in the iron region of the spectrum of the processed sample indicates migration of eroded iron from mixer (chamber or rotors) to the polymer melt. Other metals detected, e.g., cobalt, are catalyst residues from polymer production or from additives ${ }^{[23]}$.
The XRF spectrum of PET-btg contaminated with PVC shows several metals, detected both in pure processed PET and in processed PVC-contaminated PET, as shown in Figure 2. The insert in Figure 2 shows that the concentration of iron increases proportionally to the concentration of the contaminant. In Figure 3, we compare the XRF spectrum of the non-processed PVC sample, used as a contaminant, and of the rotor of the internal mixer. Strong peaks between 16 and $26 \mathrm{keV}$, in Figures 1, 2, and 4, are related to C, $\mathrm{H}$ and $\mathrm{O}$, present in large concentrations in the samples. The absence of metals in non-processed PVC and the coincidence of the metals present in the mixer rotor and in the processed and contaminated PET-btg samples, clearly shows that the metals detected came from the processing equipment. The increase in iron concentration as a function of PVC contamination also suggests that the hydrochloric acid produced in the thermo-mechanical degradation of the contaminant erodes the metal from the processing equipment.

The samples processed in the extruder present a similar behavior. Figure 4 shows the XRF spectra of these samples and the insert emphasizes the presence of metals and the relative increase in iron concentration as a function of PVC contamination. In Figure 4, it is possible to note that $\mathrm{Mn}$ is also extracted from the extruder screw or barrel, but was not present in the samples processed in the internal mixer.

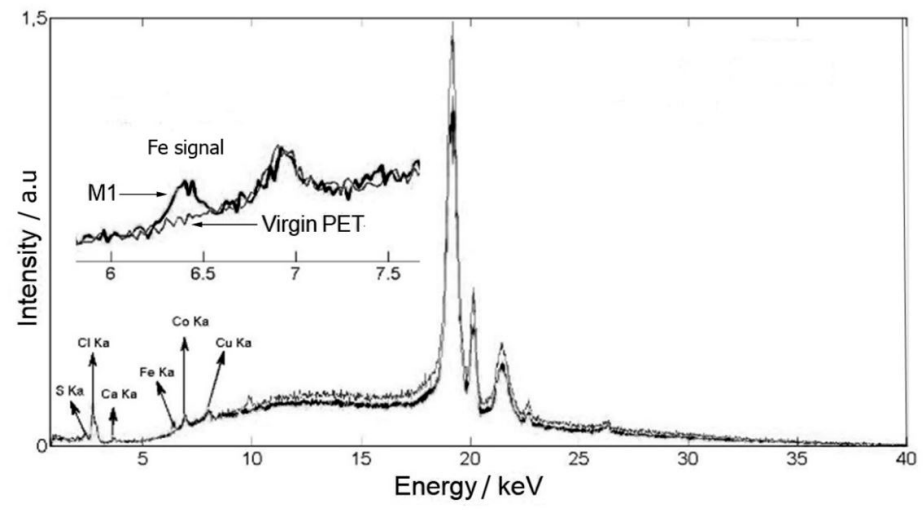

Figure 1. XRF spectra for the virgin PET-btg and M1 sample processed in the internal mixer. The insert shows a magnification of the signals assigned to iron.

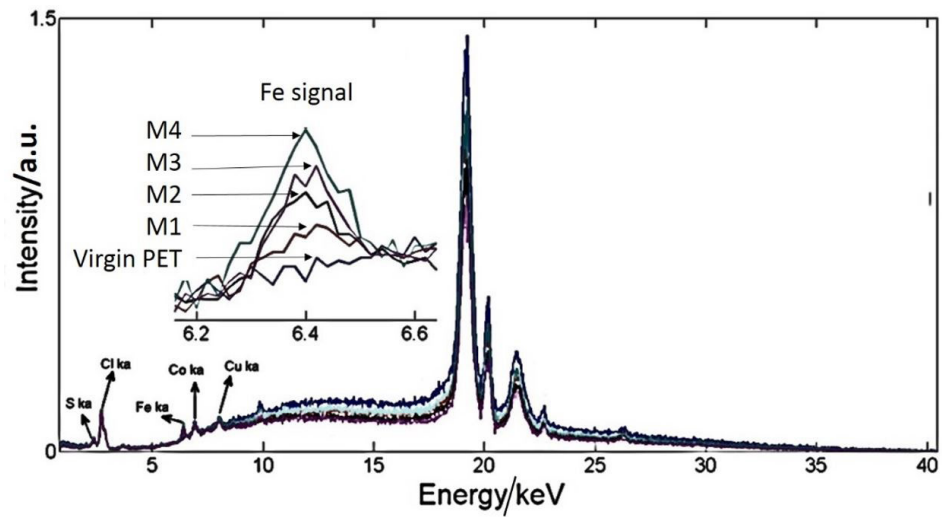

Figure 2. XRF spectra for non-processed virgin PET-btg, mixer processed pure PET-btg, M1, and for samples processed in the mixer with increasing concentrations of PVC contamination, M2-M4, see Table 4. The insert shows a magnification of the signals assigned to iron. 


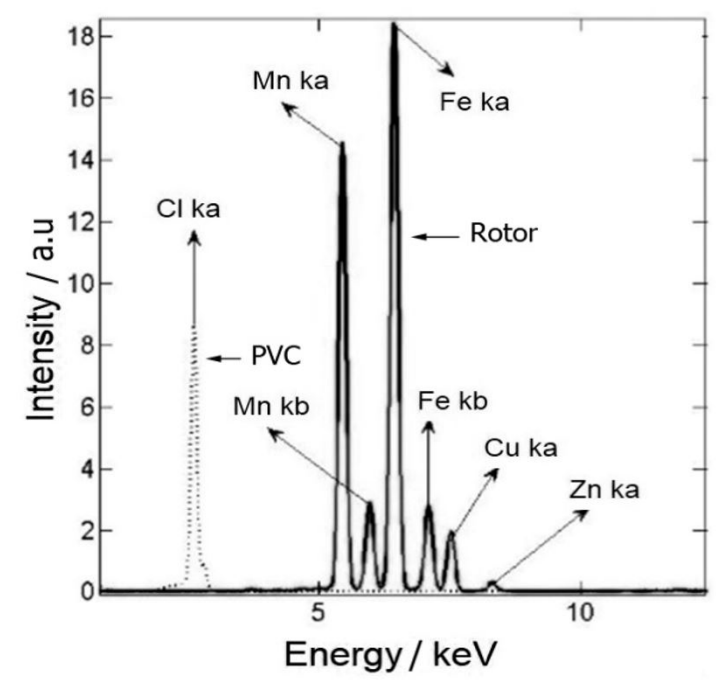

Figure 3. XRF spectra of a rotor of the internal mixer, full line, and a commercial non-processed PVC sample, dotted line.
The sizes of the screw and barrel of the extruder precluded the measurement of their XRF spectra, to confirm the origin of this metal.

\subsection{Polymers with fillers}

In Figure 5, we compare the concentration of iron in pure $\mathrm{PBT}$ and ABS with the same polymers reinforced with 30 and $20 \mathrm{wt} . \%$ of glass fibers, respectively. Samples marked P1 to P5 correspond to reinforced polymers reprocessed for one to five cycles, in a single screw extruder. Initially it is noteworthy that the glass fiber reinforced polymers exhibit a much higher concentration of iron, eroded from the extruder (screw of barrel) during its large-scale production in the processing plant, in comparison to the pure sample. This is clear evidence that the wear of the processing equipment disperse metals in the polymers. Figures $5 \mathrm{a}$ and $\mathrm{b}$ also show that PBT produced with $30 \mathrm{wt} . \%$ of glass fibers has twice the concentration of iron as ABS produced with $20 \mathrm{wt} . \%$ of the same filler, further confirming the abrasiveness of the glass fibers to the processing equipment. Figure 5 also shows that reprocessing these reinforced polymers for five

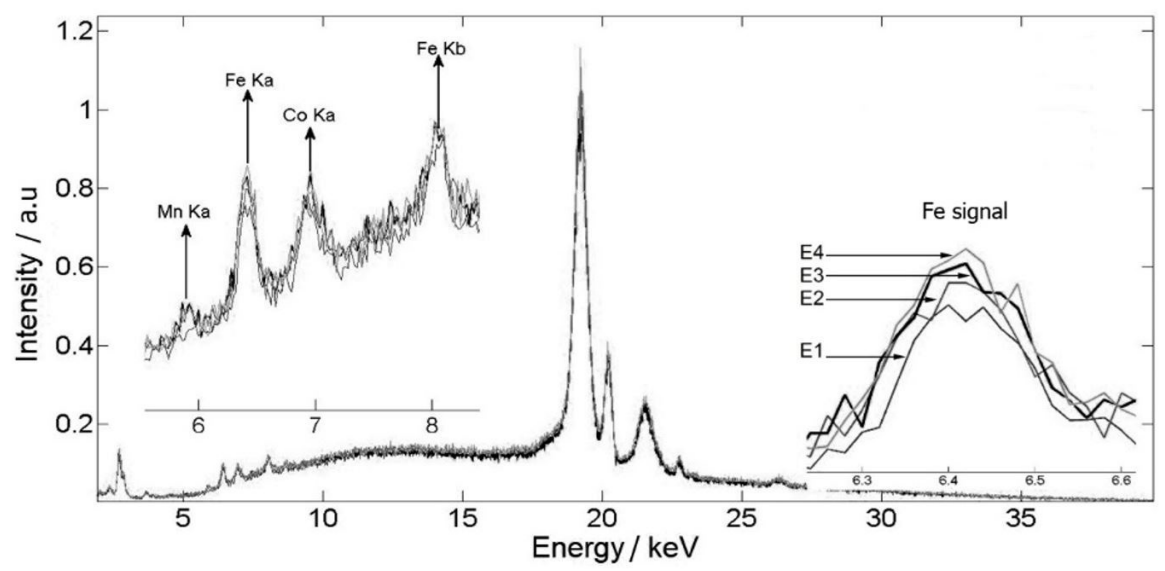

Figure 4. XRF spectra for PVC-contaminated PET samples processed in the extruder. Left insert: magnification of the spectral region for metals (6-8 keV). Right insert: magnification of the signals assigned to iron (6.2-6.6 keV) for samples E1-E4 (see Table 3).

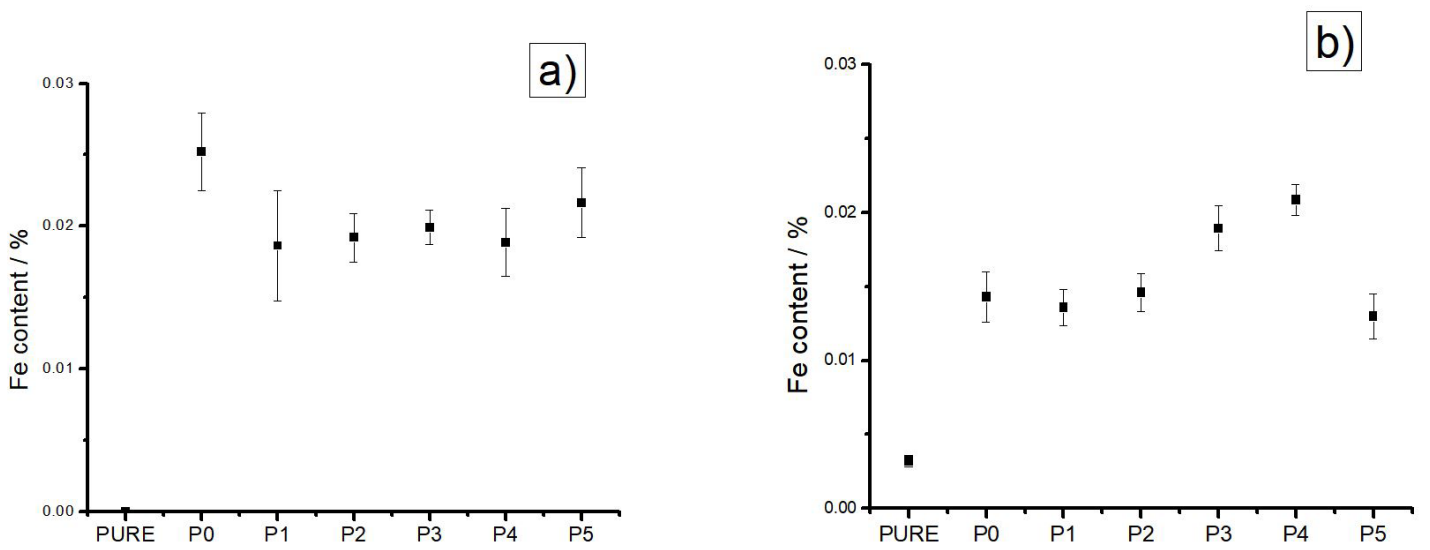

Figure 5. Plots of the Fe content as a function of material: PURE = pure sample, P0, P1, P2, P3, P4 and P5 are the number of reprocessing times of the samples reinforced with glass fibers. (a) PBT pure and reinforced with $30 \mathrm{wt} . \%$ of glass fibers and (b) ABS pure and reinforced with $20 \mathrm{wt} . \%$ of glass fibers. 

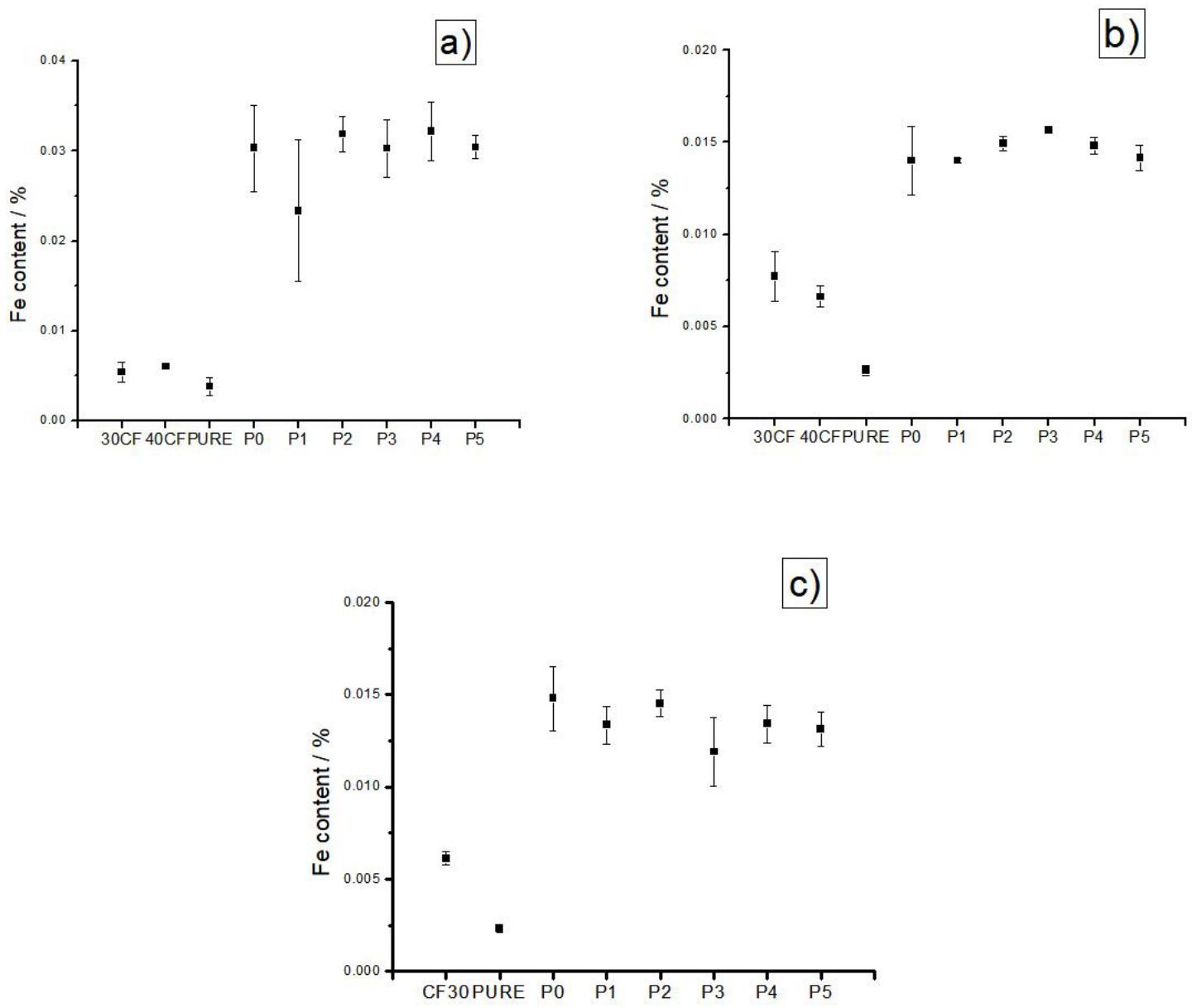

Figure 6. Plots of the Fe content as a function of material: $\mathrm{CF}=$ cellulose fiber, $\mathrm{PURE}=$ pure sample and P0, P1, P2, P3, P4 and P5 are the number of reprocessing cycles of the samples reinforced with the abrasive fillers. (a) PA- 6 with 30 and 40 wt. $\%$ of CF, pure and with $30 \mathrm{wt} \%$ of glass fibers; (b) HDPE with 30 and $40 \mathrm{wt} . \%$ of CF, pure and with $30 \mathrm{wt} . \%$ of glass fibers and (c) PP with $30 \mathrm{wt} . \%$ of CF, pure and with $20 \mathrm{wt} . \%$ of glass fibers and $10 \mathrm{wt} . \%$ of talc.

cycles, in a single screw extruder, does not significantly affect the concentration of iron in the product. The abrasive filler, dispersed in the polymer in the first extrusion, causes no further erosion in the recycling steps because it is coated with the polymer and has low contact with the processing machine parts.

In Figures 6a and b, we compare the concentration of iron in PA- 6 and pure HDPE, reinforced with 30 wt. $\%$ of glass fibers or reinforced with cellulose fibers (30 and $40 \mathrm{wt} . \%$ ). Figure $6 \mathrm{c}$ compares the iron concentration in pure PP, reinforced with $30 \mathrm{wt} . \%$ of cellulose fibers and reinforced with $20 \mathrm{wt} . \%$ of glass fibers and $10 \mathrm{wt} . \%$ of talc. For these three polymers, we also observe an increase in iron concentration comparing the pure and the reinforced polymer. However, for PA-6 reinforced with glass fibers (P0 in Figure 6a) the relative concentration of iron is two times higher in comparison to HDPE and PP also reinforced with glass fibers ( $\mathrm{P} 0$ in Figure $6 \mathrm{~b}$ and $6 \mathrm{c}$ ), probably due to the rheology of the polyamide, because they were prepared in the same equipment with the same screw design. For all polymers, the reinforcement with glass fibers or glass fibers and talc causes a significantly higher iron concentration in comparison to cellulose fibers. This lower iron content indirectly demonstrates that cellulose fibers are less abrasive to the processing equipment, which poses an additional advantage in using vegetal fibers in substitution to glass fibers on certain applications. Reprocessing of the glass fiber reinforced polymers for five cycles did not cause any significant variations in the iron content.

Atmospheric oxygen oxidizes metallic iron to produce oxides. However, we did not determine the type of iron oxide dispersed in the polymers. Previous work with talc-reinforced PP contaminated with iron oxide demonstrates that this impurity accelerates the polymer degradation reaction $\mathbf{s}^{[24]}$. The iron detected in this work remains dispersed in the polymers during its use and may accelerate the polymer degradation reactions.

\section{Conclusions}

We used X-ray fluorescence spectroscopy to demonstrate migration to the polymer melt of metals, with emphasis on iron, resulting from the wear of mixer rotors and extruder screws during melt processing of PET pure or contaminated 
with PVC. The iron concentration depends on the presence of the corrosive contaminant. We also demonstrated the presence of iron in other thermoplastics processed with abrasive reinforcing fillers like glass fibers, talc or vegetal fibers. The last being the less aggressive fillers.

Additionally, we propose the determination of the concentration of metals in extruded polymers as an easy and simple approach to follow equipment wear, thus avoiding disassembling screws and barrels for inspection and measurement off site.

\section{Acknowledgements}

The authors thank Braskem (Triunfo, Brazil), SABIC (Campinas, Brazil) and Borealis (Itatiba, Brazil) for supplying the materials. We also thank Prof. Elias A.G. Zagatto for suggestions. Work financed by São Paulo Research Foundation, FAPESP (grant number 2010/17804-7).

\section{References}

1. Griskey, R. G. (1995). Polymer process engineering: a modern approach (pp. 278-310). London: Chapman and Hall. http:// dx.doi.org/10.1007/978-94-011-0581-1_7.

2. Reifenhäuser Reiloy. (2015). Barrel and screw handbook (10th ed., pp. 35-36). Reiloy: Reifenhäuser Gruppe.

3. Reifenhäuser Reiloy. (2015). Barrel and screw handbook (10th ed., pp. 36-37). Reiloy: Reifenhäuser Gruppe.

4. Osawa, Z. (1988). Role of metals and metal-deactivators in polymer degradation. Polymer Degradation \& Stability, 20(3-4), 203-236. http://dx.doi.org/10.1016/0141-3910(88)90070-5.

5. Assadi, R., Colin, X., \& Verdu, J. (2004). Irreversible structural changes during PET recycling by extrusion. Polymer, 45(13), 4403-4412. http://dx.doi.org/10.1016/j.polymer.2004.04.029.

6. Awaja, F., \& Pavel, D. (2005). Recycling of PET. European Polymer Journal, 41(7), 1453-1477. http://dx.doi.org/10.1016/j. eurpolymj.2005.02.005.

7. Hjertberg, T., \& Sörvik, E. M. (1984). Thermal Degradation of PVC. In E. D. Owen (Ed.), Degradation and stabilization of $P V C$ (pp. 21-80). Essex: Elsevier Applied Science Publishers. http://dx.doi.org/10.1007/978-94-009-5618-6_2.

8. Goss, B. G. S., Nakatani, H., George, G. A., \& Terano, M. (2003). Catalyst residue effects on the heterogeneous oxidation of polypropylene. Polymer Degradation \& Stability, 82(1), 119-126. http://dx.doi.org/10.1016/S0141-3910(03)00172-1.

9. Gorghiu, L. M., Jipa, S., Zaharescu, T., Setnescu, R., \& Mihalcea, I. (2004). The effect of metals on thermal degradation of polyethylenes. Polymer Degradation \& Stability, 84(1), 7-11. http://dx.doi.org/10.1016/S0141-3910(03)00265-9.

10. Chirinos-Padrón, A. J., Hernández, P. H., \& Sufirez, F. A. (1988). Influence of metal ions on antioxidant behaviour in polypropylene. Polymer Degradation \& Stability, 20(3-4), 237-255. http://dx.doi.org/10.1016/0141-3910(88)90071-7.

11. Lehner, M., Schlemmer, D., \& Sängerlaub, S. (2015). Recycling of blends made of polypropylene and an iron-based oxygen scavenger - Influence of multiple extrusions on the polymer stability and the oxygen absorption capacity. Polymer Degradation \& Stability, 122(12), 122-132. http://dx.doi.org/10.1016/j. polymdegradstab.2015.10.020.
12. Dragunski, D. C., Freitas, A. R., Rubira, A. F., \& Muniz, E. C. (2000). Influence of iron(III) chloride on the degradation of polyisoprene and polybutadiene. Polymer Degradation \& Stability, 67(2), 239-247. http://dx.doi.org/10.1016/S01413910(99)00119-6.

13. Haber, F., \& Weiss, J. (1932). Über die Katalyse des Hydroperoxydes. Naturwissenschaft, 20(51), 948-950. http:// dx.doi.org/10.1007/BF01504715.

14. Gadioli, R., Morais, J. A., Waldman, W. R., \& De Paoli, M. A. (2014). The role of lignin in polypropylene composites with semi-bleached cellulose fibers: mechanical properties and its activity as antioxidant. Polymer Degradation \& Stability, 108(10), 23-34. http://dx.doi.org/10.1016/j.polymdegradstab.2014.06.005.

15. Guilhen, A., Gadioli, R., Fernandes, F. C., Waldman, W. R., \& Aurelio De Paoli, M. (2017). High density polyethylene biocomposites reinforced with cellulose fibers and using lignin as antioxidant. Journal of Applied Polymer Science, 134(35), 45219. http://dx.doi.org/10.1002/app.45219.

16. Fernandes, F. C., Gadioli, R., Yassitepe, E., \& De Paoli, M.-A. (2017). Polyamide- 6 composites reinforced with bleached or semi-bleached cellulose fibers and fabricated by extrusion. Polymer Composites, 38(2), 299-308. http://dx.doi.org/10.1002/ pc.23587.

17. Romão, W., Franco, M. F., Iglesias, A. H., Sanvido, G. B., Maretto, D. A., Gozzo, F. C., Poppi, R. J., Eberlin, M. N., \& De Paoli, M. A. (2010). Fingerprinting of bottle-grade poly(ethylene terephthalate) via matrix-assisted laser desorption/ionization mass spectrometry. Polymer Degradation \& Stability, 95(4), 666671. http://dx.doi.org/10.1016/j.polymdegradstab.2009.11.046.

18. Spinacé, M. A. S., Lucato, M. U., Ferrão, M. F., Davanzo, C. U., \& De Paoli, M. A. (2006). Determination of intrinsic viscosity of poly(ethylene terephthalate) using infrared spectroscopy and multivariate calibration method. Talanta, 69(3), 643-649. http:// dx.doi.org/10.1016/j.talanta.2005.10.035. PMid:18970616.

19. Romão, W., Franco, M. F., Bueno, M. I. M. S., Eberlin, M. N., \& De Paoli, M. A. (2010). Analysing metals in bottlegrade poly(ethylene terephthalate) by X-ray fluorescence spectrometry. Journal of Applied Polymer Science, 117(5), 2993-3000. http://dx.doi.org/10.1002/app.32232.

20. Macosko, C. W. (1994). Rheology principles, measurements, and applications. New York: VCH Publishers.

21. Cruz, S. A., Farah, M., Zanin, M., \& Bretas, R. E. S. (2008). Evaluation of rheological properties of virgin HDPE/recycled HDPE blends. Polímeros: Ciência e Tecnologia, 18(2), 144151. http://dx.doi.org/10.1590/S0104-14282008000200012.

22. Ferg, E. E., \& Rust, N. (2007). The effect of Pb and other elements found in recycled polypropylene on the manufacturing of lead-acid battery cases. Polymer Testing, 26(8), 1001-1014. http://dx.doi.org/10.1016/j.polymertesting.2007.07.001.

23. Pawlak, A., Pluta, M., Morawiec, J., Galeski, A., \& Pracella, M. (2000). Characterization of scrap poly(ethylene terephthalate). European Polymer Journal, 36(9), 1875-1884. http://dx.doi. org/10.1016/S0014-3057(99)00261-X.

24. Nakatani, H., Shibata, H., Miyazaki, K., Yonezawa, T., Takeda, H., Azuma, Y., \& Watanabe, S. (2010). Studies on heterogeneous degradation of polypropylene/talc composite: effect of iron impurity on the degradation behavior. Journal of Applied Polymer Science, 115(1), 167-173. http://dx.doi. org/10.1002/app.31010.

Received: Oct. 19, 2017

Revised: Nov. 13, 2018

Accepted: Feb. 20, 2019 